\title{
Kuman, Memlûk, Ermeni Kıpçak ve Karay Türkçelerindeki Kip Eklerinde Görülen Farklılıklar Üzerine
}

\section{Abdulkadir ÖZTÜRK 1}

\begin{abstract}
$\ddot{\mathbf{O} z}$
Tarihte Kıpçak Türkçesi, Kuman-Kıpçak boylarını teşkil eden ve Deşt-i Kıpçak, Güney Rusya, Kırım, Doğu Avrupa, Mısır ve Suriye coğrafyalarında yaşayan Kıpçak Türklerin konuşma ve yazı dilidir. Bununla birlikte Kıpçak Türkçesi çağdaş temsilcileriyle günümüzde en geniş coğrafyada varlığını devam ettiren bir Türk lehçesidir. Kıpçak Türkçesinin tarihî kolları arasında gösterilen Kuman, Ermeni Kıpçak ve Memlûk Kıpçak Türkçeleri ile Kıpçak Türkçesinin hem tarihî hem çağdaş dönemleri içerisinde yer alan Karay Türkçesi sosyo-linguistik açıdan karşılaştırmalı olarak incelenmesi gereken önemli lehçelerdir. Aralarındaki dilbilgisel ortaklıklar ve farklılıklar onların Türk dili içerisindeki yerlerini tespit etme ve Kıpçak Türkçesinin tarihî seyrini ortaya koyma bakımından da özgün bir değer taşımaktadır. Kuman Türkçesi, 14. yüzyılda yazılmış olduğu kabul edilen Codex Cumanicus adlı eserle; Memlûk Türkçesi, 14-15. yüzyıllarda Memlûk devleti sınırları içerisinde meydana getirdiği eserlerle; Ermeni Kıpçak Türkçesi, Doğu Avrupa'da 16-17. yüzyıllar arasında ortaya koyduğu eserlerle; Karay Türkçesi de 16-21. yüzyıllar arasında Kırım başta olmak üzere Doğu Avrupa'da kaleme aldığı eserlerle yazı dili olmuş lehçelerdir. Dilbilgisi çalışmalarında şekil özellikleri konusu içerisinde kip ekleri özel bir yere sahiptir. Öyle ki kip ekleri kimi zaman bir dilin, lehçenin ya da ağzın tarihî seyrine ışık tutarak lehçeler arası değişim ve etkileşimi de ortaya koyabilmektedir. Bu çalışmada Kuman, Memlûk, Ermeni Kıpçak ve Karay Türkçelerinde kullanılan kip ekleri ortaya konularak bu lehçelerdeki kip eklerinde görülen farklılıklar tespit edilecek ve konu ile ilgili değerlendirmelerde bulunulacaktır.
\end{abstract}

Anahtar kelimeler: Kuman, Memlûk, Ermeni Kıpçak, Karay, kip ekleri.

\section{On the Differences in Modal Suffixes of Cuman, Mameluke, Armenian Kipchak and Karaim Dialects}

\begin{abstract}
In history, the Kipchak Turkic are the speech and writing language of the Kipchak Turks which constitute the Kuman-Kipchak tribes and the living in the regions to Deşt-i Kipchak, South Russia, Crimea, Eastern Europe, Egypt and Syria. However, Kipchak Turkic is a Turkish dialect that continues its entity in the largest geographical area nowadays with its contemporary representatives. Cuman, Armenian Kipchak and Mameluke Kipchak dialects of Turkic are among the historical branches of Kipchak Turkic. These dialects and Karaim dialect which is in both historical and contemporary periods of Kipchak Turkic are important dialects which should be studied comparatively in terms of sociolinguistic. There are some grammatical partnerships and differences between these dialects. This situation is also important in terms of to determine their place in the Turkic language history and revealing the historical development of Kipchak Turkic. The only work of Cuman Turkic is Codex Cumanicus, which is considered to have been written in the 14th century. Mameluke Turkic works were written in the borders of the Mameluke state for centuries, in the 14th-
\end{abstract}

Dr. Öğr. Üyesi, Ordu Úniversitesi, Fen Edebiyat Fakültesi, Türk Dili ve Edebiyatı Bölümü, akadirozturk@odu.edu.tr, [Makale kaylt tarihi: 9.7.2018-kabul tarihi:15.8.2018] 
15th centuries. The works of Armenian Kipchak Turkic are written in Eastern Europe, in 16th-17th centuries. The works of Karaim Turkic were written also in Eastern Europe, especially in the Crimea, for 16th-21st centuries. At the same time, these works are important in terms of literary languages. In the grammatical studies, the modal suffixes have a special place in the shape features. Such that the modal suffixes can exhibit the changes and interactions between dialects by shedding light on the history of a language and dialect. In this study, the modal suffixes used in Cuman, Mameluke, Armenian Kipchak and Karaim Turkic are introduced and the differences observed in the modal suffixes in these dialects will be determined and the related evaluations will be made.

Key words: Cuman, Mameluke, Armenian Kipchak, Karaim, modal suffixes.

\section{Giriş}

Kıpçak Türkçesi, geniş bir coğrafyada 14. yüzyıldan günümüze kadar yazı dili olarak kullanılan Türk dilinin bir koludur. Kıpçak Türkçesinin ilk yazılı kaynă̆ı Codex Cumanicus'tur. 14. yüzyılın hemen başlarında yazıldığı düşünülen bu eser ile birlikte Kıpçak Türkçesi tarih boyunca farklı alfabelerin kullanılmasıyla eserler meydana getirmiştir.

Çalışmaya konu olan lehçeler, Kuman Türkçesi (14. yüzyll), Memlûk Türkçesi (15.-16. yüzyıllar), Ermeni Kıpçak Türkçesi (16.-17. yüzyıllar) ve Karay Türkçesi (16.-20. yüzyıllar) olarak, tarihsel süreçleri ve yazılı kaynakları göz önünde bulundurulmak suretiyle bu sirayla verilmektedir.

Yazılı kaynaklardan hareketle Kıpçak Türkçesinin lehçeleri, ağızları, tarihsel gelişim- değişim ve farklılaşmaları ve dilbilgisel bütün özellikleri üzerine yapılan çalışmalar, bu lehçenin Türk dili içerisindeki yerini belirlemede referans olmakla birlikte, tarihî ve çağdaş dönemlerini karşılaştırma imkânı da sağlamaktadır. Aynı zamanda bu çalışmalar, Kıpçak Türkçesi lehçelerinin birbirleri arasındaki ortak ve farklı yönlerin tespitine de kaynaklık etmektedir.

Bu çalışmada, her biri farklı alfabeler ile yazılı eserler veren Kuman, Memlûk, Ermeni Kıpçak ve Karay Türkçelerindeki kip ekleri karşılaştırılarak ortaya çıkan farklılıklar üzerinde durulmaktadır.

\section{Haber Kipleri}

\section{Geçmiş Zaman}

\section{Görülen Geçmiş Zaman}

\begin{tabular}{|c|c|c|c|}
\hline $\begin{array}{c}\text { Kuman } \\
\text { Türkçesi }\end{array}$ & $\begin{array}{c}\text { Memlûk } \\
\text { Türkçesi }\end{array}$ & $\begin{array}{c}\text { Ermeni Kıpçak } \\
\text { Türkçesi }\end{array}$ & $\begin{array}{c}\text { Karay } \\
\text { Türkçesi }\end{array}$ \\
\hline$-\mathrm{DX}^{2}$ & $-\mathrm{DX}$ & $-\mathrm{DX}$ & $-\mathrm{DX}$ \\
\hline
\end{tabular}

Görülen geçmiş zaman eki bu dört lehçe arasında bir farklılık göstermemektedir. Ancak Karay Türkçesinde, bu kipin \{-di\} kullanımının 3. çokluk şahıs olumsuz çekiminde kiel'miad'liar 'gelmediler', ürimiuad'liar 'yürümediler' örneklerinde olduğu gibi \{-d'\} şeklini aldığı görülür.

\footnotetext{
2 Bu çalışmada geçen eklerin gösteriminde kullanılan büyük harflerin karşılığı şu şekildedir: -X: -1, -i, -u, -ü; -I: -1, -i; -U: u, -ü; -A: -a, -e; -E: -e, -è; -D: -d, -t; -G: -g, -k. 


\section{Duyulan Geçmiş Zaman}

\begin{tabular}{|c|c|c|c|}
\hline $\begin{array}{c}\text { Kuman } \\
\text { Türkçesi }\end{array}$ & $\begin{array}{c}\text { Memlûk } \\
\text { Türkçesi }\end{array}$ & $\begin{array}{c}\text { Ermeni Kıpçak } \\
\text { Türkçesi }\end{array}$ & $\begin{array}{c}\text { Karay } \\
\text { Türkçesi }\end{array}$ \\
\hline$-p$ & $-p$ & $-p$ & - \\
\hline$-p t X r$ & $-p t X r$ & $-p t X r$ & - \\
\hline$-m I s ̧ ~$ & $-m X s ̧$ & - & $-G A n,-G A n l A r$ \\
\hline
\end{tabular}

Kuman ve Memlûk Türkçelerinde duyulan geçmiş zaman kipi için 3 farklı ek kullanılmakla birlikte aynı eklerin kullanılması sebebiyle bir ortaklık da söz konusudur. Ermeni Kıpçak Türkçesinde duyulan geçmiş zaman kipi bu iki lehçeyle büyük oranda benzerlik gösterir. Bu dört lehçe arasında önemli farklllıklardan biri Ermeni Kıpçak Türkçesi ve Karay Türkçesi metinlerinde \{-mIş\} geçmiş zaman ekinin kullanılmadığının tespit edilmesidir. Kuman ve Memlûk Türkçelerinde yer almayan \{-GAn\} duyulan geçmiş zaman ekinin Ermeni Kıpçak ve Karay Türkçelerinde ortaklık göstermesi de ayrıca dikkate değerdir. Karay Türkçesinde bu kip için sadece 3. kişi çekimlerinde sıylangan 'saygı görmüş' (KA 9/3), saxışlanganlar 'düşünülmüşler' (KA 9/2) örneklerinde görüldüğü üzere $\{$-GAn\}/\{-GAnlAr\} ekinin kullanılması Karay Türkçesinin diğer lehçeler ile bu kipte büyük ölçüde farklılaştığını göstermektedir.

\section{Geniş Zaman}

\begin{tabular}{|c|c|c|c|}
\hline $\begin{array}{c}\text { Kuman } \\
\text { Türkçesi }\end{array}$ & $\begin{array}{c}\text { Memlûk } \\
\text { Türkçesi }\end{array}$ & $\begin{array}{c}\text { Ermeni Kıpçak } \\
\text { Türkçesi }\end{array}$ & $\begin{array}{c}\text { Karay } \\
\text { Türkçesi }\end{array}$ \\
\hline$-\mathrm{r}$ & $-\mathrm{r}$ & $-\mathrm{r}$ & - \\
\hline$-\mathrm{Ar}$ & $-\mathrm{Ar}$ & $-\mathrm{Ar}$ & - \\
\hline$-\mathrm{Xr}$ & $-\mathrm{Xr}$ & $-\mathrm{Xr}$ & - \\
\hline$-\mathrm{A},-\mathrm{X}$ \\
$(\mathrm{r}$ düşmesiyle $)$
\end{tabular}

Geniş zaman kipi Kuman, Memlûk ve Ermeni Kıpçak Türkçelerinde genel olarak benzerlik göstermektedir. Bu üç lehçe arasındaki tek farklılık olarak; Kuman Türkçesinde bazı örneklerde tespit edilen $\{-\mathrm{Ar}\},\{-\mathrm{Ir}\}$ ve \{-Ur\} eklerindeki /-r/ ünsüzünün düşmesi sonucu baru-mén 'giderim', tüvürü mèn 'çeviririm' ( $\mathrm{CC}$ 101) örneklerinde olduğu gibi /-A/, /-I/, /-U/ ünlülerinin kip eki görevini üstelenmesi gösterilebilir. Karay Türkçesinde geniş zaman kipi ünsüzlerden sonra $\{-\mathrm{A}\}$ ve ünlülerden sonra ise $\{-y\}$ ekleriyle çekimlenmektedir. 
Gülsevin'e göre Karay Türkçesinde, başlamış ve devam eden zamanın bildirildiği bu çekim için \{-(y)A\} eki kullanılır. Ancak ünlüyle biten fiillere eklendiğinde; $\{-\mathrm{yA}\}$ ekinin sonundaki ünlünün kaybolması sonucu bu ek, $\{-\mathrm{y}\}$ şeklinde kullanılmaya başlanmıştır: izleymin 'ararım/arıyorum', kılasın 'yaparsin/yapıyorsun' (Gülsevin 2016: 83).

Ermeni Kıpçak Türkçesinde bu kipin olumsuz çekiminde \{-mas/-mes\} eki \{-man/-män\} şeklini alır: bilmes men > bilmän (Kasapoğlu Çengel 2012: 52).

Karay Türkçesinde $\{-y\}$ ile kurulan geniş ve şimdiki zaman kiplerinin olumsuz çekimlerinde $\{-\mathrm{mA}\}$ olumsuzluk ekinde, kip ekinin etkisiyle ünlü daralması görülür ve bu basit zaman çekimlerinde olumsuzluk eki \{-mI\} şeklini alır: körmiydirlär 'görmezler' (KTD 85), bilmiymin 'bilmiyorum' (KTD 84).

\section{Şimdiki Zaman}

\begin{tabular}{|c|c|c|c|}
\hline $\begin{array}{c}\text { Kuman } \\
\text { Türkçesi }\end{array}$ & $\begin{array}{c}\text { Memlûk } \\
\text { Türkçesi }\end{array}$ & $\begin{array}{c}\text { Ermeni Kipçak } \\
\text { Türkçesi }\end{array}$ & $\begin{array}{c}\text { Karay } \\
\text { Türkçesi }\end{array}$ \\
\hline -AdXr & - AdXr & - & - \\
\hline -ydIr & - ydIr & - & - \\
\hline$-(\mathrm{U}) \mathrm{pdUr}$ & - & - & - \\
\hline- & $-\mathrm{yor} /-\mathrm{yorur}$ & - & - \\
\hline- & $-(\mathrm{X}) \mathrm{y}$ & $-(\mathrm{X}) \mathrm{XXr}$ & - \\
\hline- & $-(\mathrm{X}) \mathrm{yXr}$ & $-\mathrm{IIr}$ & $-\mathrm{A}$ \\
\hline- & - & - & $-\mathrm{y}$ \\
\hline
\end{tabular}

Şimdiki zaman kipi Kuman Türkçesinde 3, Memlûk Türkçesinde 5, Ermeni Kupçak ve Karay Türkçelerinde ise 2 farklı ek ile çekimlenmektedir. Kuman ve Memlûk Türkçelerinde \{-AdXr\} ve \{-ydIr\} ekleri ortaktır. Kuman Türkçesinde \{-(U)pdUr\} eki daha çok duyulan geçmiş zaman eki olarak kullanılmakla birlikte şimdiki zaman eki olarak da çırmaluptur 'sarılıyor' (CC 104) kullanılmıştır. Bu durum diğer üç lehçede görülmemektedir.

\{-(X)yXr\} şimdiki zaman ekinin kullanımlarına Memlûk ve Ermeni Kıpçak Türkçelerinde rastlanılır. \{(I)y\} eki ise Memlûk ve Karay Türkçelerinde benzerlik gösterir.

Şimdiki zaman kipinde $\{$-yor $\} /\{$-yorur $\}$ eki yatayor 'yatıyor', kèteyorur 'gidiyor' (KTG 223) sadece Memlûk Türkçesinde, \{-IIr\} eki biliirmen 'biliyorum' (EHKT 51) sadece Ermeni Kıpçak Türkçesinde ve \{-A\} eki ise çağıramın 'sesleniyorum' (KTD 83) sadece Karay Türkçesinde görülen eklerdir. Kuman, Memlûk ve Ermeni Kıpçak Türkçelerinde geniş zaman ve şimdiki zaman kiplerinin, müstakil kullanılan 
eklerle ayrımı sağlanırken; Karay Türkçesinde geniş ve şimdiki zaman kipleri aynı eklerle karşılandığı için bu ayrımdan söz edilemez.

\section{Gelecek Zaman}

\begin{tabular}{|c|c|c|c|}
\hline $\begin{array}{c}\text { Kuman } \\
\text { Türkçesi }\end{array}$ & $\begin{array}{c}\text { Memlûk } \\
\text { Türkçesi }\end{array}$ & $\begin{array}{c}\text { Ermeni Kupçak } \\
\text { Türkçesi }\end{array}$ & $\begin{array}{c}\text { Karay } \\
\text { Türkçesi }\end{array}$ \\
\hline- GAy & - GAy & - GAy & - \\
\hline- & - & $-\mathrm{sAr}$ & - \\
\hline- & - & - AsI & - \\
\hline- & - & $-\mathrm{I}$ & $-\mathrm{I}$ \\
\hline- & - & - & $-\mathrm{Ar}$ \\
\hline- & - & - & $-\mathrm{Xr}$ \\
\hline- & - & - & $\mathrm{r}$ \\
\hline- & - & - & - \\
\hline
\end{tabular}

Tabloda görüldüğü üzere \{-GAy\} gelecek zaman eki, Kuman, Memlûk ve Ermeni Kıpçak Türkçelerinde kullanılan ortak bir ektir. Aynı zamanda bu ek, Kuman ve Memlûk Türkçelerinde gelecek zaman kipi için kullanılan tek ektir. Ermeni Kıpçak Türkçesinde bu ekin yanı sıra işlek olmamakla birlikte \{-sAr\}, \{-AsI\} ekleri ve örnekleriyle çokça karşılaşılan $\{-\mathrm{I}\}$ eki de gelecek zaman kipi için kullanılmıştır.

Modern Kıpçak yazı dillerinde $\{-\mathrm{A}\}$ şeklinde gelecek zamanı ve şimdiki zamanı bildiren bu ek, Ermeni Kıpçak Türkçesinde açık orta hecede daralmak suretiyle $\{-\mathrm{I}\}$ şeklini alarak tanıxlı berisen 'tanıklık edeceksin', bağlama göre gelecek zamanı veya şimdiki zamanı bildirir (Kasapoğlu Çengel 2012: 54).

Karay Türkçesinde gelecek zaman kipi, diğer lehçelerde, özellikle Kuman Türkçesinde geniş zaman kipi için kullanılan $\{-\mathrm{I}\},\{-\mathrm{U}\},\{-\mathrm{Ar}\},\{-\mathrm{Xr}\}$ ve $\{-\mathrm{r}\}$ ekleriyle çekimlenmektedir. Bu durum gelecek zaman kipinde Karay Türkçesine has bir özelliktir.

\section{Tasarlama Kipleri}

\section{Emir Kipi}

\begin{tabular}{|c|c|c|c|c|}
\hline Şahıslar & $\begin{array}{c}\text { Kuman } \\
\text { Türkçesi }\end{array}$ & $\begin{array}{c}\text { Memlûk } \\
\text { Türkçesi }\end{array}$ & $\begin{array}{c}\text { Ermeni Kıpçak } \\
\text { Türkçesi }\end{array}$ & $\begin{array}{c}\text { Karay } \\
\text { Türkçesi }\end{array}$ \\
\hline I. Teklik & -Ayım, -GAyIm, -yIm & -Ayım, -GAyIm & -(I)yIm & -(A)yIm \\
\hline II. Teklik & -Ø, -GIl & $-\varnothing,-$ GIl, -GIn & $-\varnothing,-$ GIn & $-\varnothing,-$ GIn \\
\hline III. Teklik & -sIn, -sUn & -sIn, -sUn & -sIn, -sUn & -sIn, -sUn \\
\hline I. Çokluk & -AlIm, -GAlIm, -lXm, & -AlIm, -GAlIm, & -lIk, -AlIk & -(A)yIk \\
\hline
\end{tabular}




\begin{tabular}{|c|c|c|c|c|}
\hline & -lIy, -AlI, -lXk & -AlIk & & \\
\hline II. Çokluk & 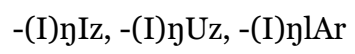 & $-\eta,-n I z$ & $-(\mathrm{I}) \mathrm{\eta Iz}$ & -(I)yIz \\
\hline III. Çokluk & -sInlAr, -sUnlAr & -sInlAr, -sUnlAr & -sInlAr, -sUnlAr & -sInlAr, -sUnlAr \\
\hline
\end{tabular}

Emir kipinin 2. teklik şahıs çekiminde Kuman ve Memlûk Türkçelerinde görülen \{-GIl\} eki Kıpçak-Oğuz etkileşimi veya müstensih hataları sonucu bu lehçelere ait metinlerde görülmektedir3. Kıpçak Türkçesinde emir kipi 2. teklik şahısta ya eksizdir ya da \{-GIn\} eki ile yapılmaktadır. Argunşah ve Güner'e göre \{-GIn\} ekini düzenli olarak kullanan tek Türk lehçesi Ermeni Harfli Kıpçak Türkçesidir (Argunşah-Güner 2015: 106). Karay Türkçesinde de \{-GIn\} ekinin düzenli kullanıldığı eşitkin 'işit' (KTD 89) görülmektedir.

Bu lehçeler arasında emir kipinde görülen önemli farklılık olarak Kuman Türkçesinde bu kipin 1. çokluk şahıs çekiminde kullanılan eklerin çeşitliliği gösterilebilir.

\section{İstek Kipi}

\begin{tabular}{|c|c|c|c|}
\hline $\begin{array}{c}\text { Kuman } \\
\text { Türkçesi }\end{array}$ & $\begin{array}{c}\text { Memlûk } \\
\text { Türkçesi }\end{array}$ & Ermeni Kıpçak Türkçesi & $\begin{array}{c}\text { Karay } \\
\text { Türkçesi }\end{array}$ \\
\hline$-\mathrm{A}$ & $-\mathrm{A}$ & - & $-\mathrm{GEy}$ \\
\hline
\end{tabular}

İstek kipi için müstakil bir ek bulunmayan Ermeni Kıpçak Türkçesinde bu kip, emir kipi ile karşllanmaktadır. Kuman, Memlûk ve Ermeni Kıpçak Türkçelerinde gelecek zaman kip eki olarak kullanılan \{-GAy\} eki, Karay Türkçesinde ince sıradan ünlüye geçmek suretiyle \{-GEy\} şeklinde yetişkeymin 'olgunlaşayım' (KTD 90) fiillerin istek kipi çekiminde kullanılmaktadır.

\section{Şart Kipi}

\begin{tabular}{|c|c|c|c|}
\hline $\begin{array}{c}\text { Kuman } \\
\text { Türkçesi }\end{array}$ & $\begin{array}{c}\text { Memlûk } \\
\text { Türkçesi }\end{array}$ & Ermeni Kipçak Türkçesi & $\begin{array}{c}\text { Karay } \\
\text { Türkçesi }\end{array}$ \\
\hline -sA & $-\mathrm{sA}$ & $-\mathrm{sA}$ & $-\mathrm{sA},-\mathrm{sE}$ \\
\hline
\end{tabular}

Şart kipinde görülen tek farklılık Karay Türkçesinde 2. şahıs çekimlerde, şahıs eklerine bağlı olarak şart kipi ekinin kalın sıradan ünlülü fiillere sorsäy ‘sorsan', yeberseyiz ‘indirirseniz' (KTD 92) örneklerinde olduğu gibi $\{$-sä\} şeklinde gelmesidir.

\section{Gereklilik Kipi}

\begin{tabular}{|c|c|c|c|}
\hline $\begin{array}{c}\text { Kuman } \\
\text { Türkçesi }\end{array}$ & $\begin{array}{c}\text { Memlûk } \\
\text { Türkçesi }\end{array}$ & $\begin{array}{c}\text { Ermeni Kıpçak } \\
\text { Türkçesi }\end{array}$ & $\begin{array}{c}\text { Karay } \\
\text { Türkçesi }\end{array}$ \\
\hline -mA kerek & - & - & -mA keräk (3. şahısta) \\
\hline
\end{tabular}

$3 \quad$ Kuman ve Memlûk Türkçelerinde emir kipinin 2. teklik şahıs çekiminde görülen \{-GIl\} eki, bu tarihî lehçelerin yanı sıra çağdaş Kıpçak lehçelerinden Kırgız, Karakalpak ve Kumuk Türkçelerinde de aynı işlevle kullanılmaktadır. 


\begin{tabular}{|c|c|c|c|}
\hline -mAh kerek & -mAK kerek & - mAh kerek & - \\
\hline -mAGA kerek & - & - & - \\
\hline- & - Ar kerek & - & - \\
\hline- & - sA kerek & - & - \\
\hline- & - & - -mAlI & - \\
\hline- & - & - GAy kerek & - \\
\hline- & - & -GA tiyäsidir & - \\
\hline- & - & -GA tiyişlidir & - \\
\hline
\end{tabular}

Gereklilik kipi dört lehçede, kiplik ifade eden kerek sözcüğünün oluşturduğu yapıların kullanılması bir ortaklıktır. Gereklilik kip eklerinin Memlûk ve Ermeni Kıpçak Türkçelerinde çeşitlendiği söylenilebilir.

Ermeni Kıpçak Türkçesinde işlek bir kullanıma sahip \{-GA tiyäsidir/tiyişlidir/tiyär\} şeklinde analitik yapıdaki gereklilik kip ekleri, öznenin yönelme hâli ekini alması ve ardından tiyäsidir/tiyişlidir ve nadiren tiyär modal sözlerinin getirilmesiyle ortaya çıkmıştır: tiyişlidir maya yazmaga 'benim yazmam gerekir/ben yazmalıyım' (Kasapoğlu Çengel 2012: 56). Ayrıca éşitmeli ‘işitmeli’ örneğinde görüldüğü gibi Ermeni Kıpçak Türkçesi metinlerinde çok az örneğine rastlanılan \{-mAlI\} eki de gereklilik kipi çekiminde kullanılmıştır: (Güner 2013: 249).

Karay Türkçesinde gereklilik kipi sadece 3. şahıs çekimlerinde görülmektedir.

\section{Birleşik Zamanlar}

\section{Görülen Geçmiş Zaman Kipinin Hikâyesi}

\begin{tabular}{|c|c|c|c|}
\hline Kuman & Memlûk & Ermeni Kıpçak Türkçesi & $\begin{array}{c}\text { Karay } \\
\text { Türkçesi }\end{array}$ \\
\hline Türkçesi & -DX eresi & -DX e-di & - \\
\hline
\end{tabular}

Görülen geçmiş zaman kipinin hikâye birleşik çekiminde dört lehçe arasındaki belirgin farklılık, bu yapıdaki birleşik kipli fiillerin Karay Türkçesinde görülmemesidir.

\section{Duyulan Geçmiş Zaman Kipinin Hikâyesi}

\begin{tabular}{|c|c|c|c|}
\hline $\begin{array}{c}\text { Kuman } \\
\text { Türkçesi }\end{array}$ & $\begin{array}{c}\text { Memlûk } \\
\text { Türkçesi }\end{array}$ & $\begin{array}{c}\text { Ermeni Kpçak } \\
\text { Türkçesi }\end{array}$ & $\begin{array}{c}\text { Karay } \\
\text { Türkçesi }\end{array}$ \\
\hline -mIş e-di & $-m X s ̧$ e-di & - & - \\
\hline- & $-p$ e/er-di & $-p$ e-di & - \\
\hline
\end{tabular}




\begin{tabular}{|c|c|c|c|}
\hline- & $-p t X r$ e/er-di & - & - \\
\hline- & - & -GAn e-di & -GAn e-di \\
\hline
\end{tabular}

Duyulan geçmiş zaman kipinin hikâyesi birleşik çekiminde Memlûk Türkçesinde ek çeşitliliği görülmektedir. Kuman-Memlûk, Memlûk-Ermeni Kıpçak ve Ermeni Kıpçak-Karay Türkçeleri arasında kısmen ortaklıklar bulunmaktadır. Duyulan geçmiş zaman kip ekleri dikkate alındığında bu birleşik çekimde, Ermeni Kıpçak ve Karay Türkçeleri diğer lehçelerle önemli ölçüde farklılık göstermektedirler.

\section{Geniş Zaman Kipinin Hikâyesi}

\begin{tabular}{|c|c|c|c|}
\hline $\begin{array}{c}\text { Kuman } \\
\text { Türkçesi }\end{array}$ & $\begin{array}{c}\text { Memlûk } \\
\text { Türkçesi }\end{array}$ & Ermeni Kıpçak Türkçesi & $\begin{array}{c}\text { Karay } \\
\text { Türkçesi }\end{array}$ \\
\hline -r e-di & -r e/er-di & -r e-di & -r e-di \\
\hline -Xr e-di & $-X r$ e/er-di & $-X r$ e-di & - Xr e-di \\
\hline- & -Ar e/er-di & -Ar e-di & -Ar e-di \\
\hline
\end{tabular}

Bu birleşik zaman çekiminde dört lehçe arasında bir farklılıktan söz etmek güçtür.

\section{Şimdiki Zaman Kipinin Hikâyesi}

\begin{tabular}{|c|c|c|c|}
\hline $\begin{array}{c}\text { Kuman } \\
\text { Türkçesi }\end{array}$ & $\begin{array}{c}\text { Memlûk } \\
\text { Türkçesi }\end{array}$ & Ermeni Kipçak Türkçesi & $\begin{array}{c}\text { Karay } \\
\text { Türkçesi }\end{array}$ \\
\hline- & $-(\mathrm{X}) \mathrm{y}$ e-di & - & - \\
\hline- & $-(\mathrm{X}) \mathrm{yXr}$ e-di & $-(\mathrm{X}) \mathrm{yXr}$ e-di & $-\mathrm{r} \mathrm{e-di}$ \\
\hline- & - & - & $-\mathrm{Xr}$ e-di \\
\hline- & - & - & $-\mathrm{Ar}$ e-di \\
\hline
\end{tabular}

Kuman Türkçesinde şimdiki zaman kipinin hikâyesi tespit edilememiştir. Şimdiki zaman kip eklerinin kullanımlarından kaynaklı farklılıklar vardır ve bunlar tabloda görülmektedir.

\section{Gelecek Zaman Kipinin Hikâyesi}

\begin{tabular}{|c|c|c|c|}
\hline $\begin{array}{c}\text { Kuman } \\
\text { Türkçesi }\end{array}$ & $\begin{array}{c}\text { Memlûk } \\
\text { Türkçesi }\end{array}$ & $\begin{array}{c}\text { Ermeni Kıpçak } \\
\text { Türkçesi }\end{array}$ & $\begin{array}{c}\text { Karay } \\
\text { Türkçesi }\end{array}$ \\
\hline -GAy e-di & -GAy e/er-di & -GAy e-di & -GEy e-dI, -GEy -t \\
\hline- & - & -sAr e-di & - \\
\hline
\end{tabular}


Gelecek zaman kipinin hikâyesi birleşik çekiminde dört lehçe arasında biçimsel farklılık görülmemekle birlikte Karay Türkçesinde bu birleşik çekim, istek kipi ekleri ile yapılmaktadır. Karay Türkçesinde \{GEy\} eki, basit zaman çekimlerinde istek kipi işlevindedir. Ancak istek kipi işlevindeki \{-GEy\} ekinin, $\{\mathrm{e}-\}$ ek-fiili ve görülen geçmiş zaman kip ekinin kurulumuyla oluşturduğu birleşik yapı ürpäygeyt 'ürperecekti' (KTD 94) örneğinde olduğu gibi semantik bakımdan gelecek zaman kipinin hikâyesini karşlamaktadır.

\section{Şart Kipinin Hikâyesi}

\begin{tabular}{|c|c|c|c|}
\hline $\begin{array}{c}\text { Kuman } \\
\text { Türkçesi }\end{array}$ & $\begin{array}{c}\text { Memlûk } \\
\text { Türkçesi }\end{array}$ & Ermeni Kıpçak Türkçesi & $\begin{array}{c}\text { Karay } \\
\text { Türkçesi }\end{array}$ \\
\hline -sA e-di & -sA e/er-di & -sA e-di & -sA e-di \\
\hline- & -sA y-dI & - & - sE y-dI \\
\hline
\end{tabular}

Şart kipinin hikâyesi birleşik çekimi dört lehçede de kullanılmakla birlikte, \{e-\} ek-fiilinden kaynaklı küçük farklılaşmalar dışında bu lehçeler arasında farklılık bulunmamaktadır.

\section{İstek Kipinin Hikâyesi}

\begin{tabular}{|c|c|c|c|}
\hline $\begin{array}{c}\text { Kuman } \\
\text { Türkçesi }\end{array}$ & $\begin{array}{c}\text { Memlûk } \\
\text { Türkçesi }\end{array}$ & Ermeni Kipçak Türkçesi & $\begin{array}{c}\text { Karay } \\
\text { Türkçesi }\end{array}$ \\
\hline- & - & - & - \\
\hline
\end{tabular}

Bu birleşik zaman çekimi dört lehçede de görülmemektedir. Ancak Karay Türkçesinde istek kipi eki ile kurulan birleşik çekim, istek kipinin hikâyesi için değil, gelecek zamanın hikâyesi için kullanılmaktadır.

\section{Gereklilik Kipinin Hikâyesi}

\begin{tabular}{|c|c|c|c|}
\hline $\begin{array}{c}\text { Kuman } \\
\text { Türkçesi }\end{array}$ & $\begin{array}{c}\text { Memlûk } \\
\text { Türkçesi }\end{array}$ & Ermeni Kıpçak Türkçesi & $\begin{array}{c}\text { Karay } \\
\text { Türkçesi }\end{array}$ \\
\hline- & - & - & mA keräk e-di \\
\hline
\end{tabular}

Kuman, Memlûk ve Ermeni Kıpçak Türkçelerinde görülmeyen gereklilik kipinin hikâyesi, sadece Karay Türkçesinde bulunmakta ve Karay Türkçesinin bu birleşik zaman çekiminde diğer üç lehçe ile farklılık göstermektedir.

\section{Geniş Zaman Kipinin Rivayeti}

\begin{tabular}{|c|c|c|c|}
\hline $\begin{array}{c}\text { Kuman } \\
\text { Türkçesi }\end{array}$ & $\begin{array}{c}\text { Memlûk } \\
\text { Türkçesi }\end{array}$ & Ermeni Kipçak Türkçesi & $\begin{array}{c}\text { Karay } \\
\text { Türkçesi }\end{array}$ \\
\hline- & $-r$ er-miş & - & - \\
\hline
\end{tabular}




\begin{tabular}{|c|c|c|c|}
\hline- & - Ar er-miş & - & - \\
\hline- & $-X r$ er-miş & - & - \\
\hline
\end{tabular}

Geniş zaman kipinin rivayeti sadece Memlûk Türkçesinde görülmektedir. Bu durum \{-mXş\} duyulan geçmiş zaman kip ekinin Memlûk Türkçesinde yaygın kullanılması ile açıklanabilir. Kuman Türkçesinde de duyulan geçmiş zaman kipi çekiminde görülen bu ekin, birleşik zamanlarda rivayet yapısını oluşturduğu örneklerine rastlanılmamaktadır. Codex Cumanicus'un Kuman Türkçesini yansıtan tek eser olmasından hareketle bu birleşik zaman biçiminin Kuman Türkçesinde kullanılıp kullanılmadığına dair kesin bir kanıya varılamamaktadır.

\section{Görülen Geçmiş Zaman Kipinin Şartı}

\begin{tabular}{|c|c|c|c|}
\hline $\begin{array}{c}\text { Kuman } \\
\text { Türkçesi }\end{array}$ & $\begin{array}{c}\text { Memlûk } \\
\text { Türkçesi }\end{array}$ & $\begin{array}{c}\text { Ermeni Kıpçak } \\
\text { Türkçesi }\end{array}$ & $\begin{array}{c}\text { Karay } \\
\text { Türkçesi }\end{array}$ \\
\hline -DX e/er-se & -DX e/er-sA & -DX e-se & -DX e-sä \\
\hline
\end{tabular}

Görülen geçmiş zaman kipinin şartı birleşik çekiminde dört lehçe ortaklık göstermektedir.

\section{Duyulan Geçmiş Zaman Kipinin Şartı}

\begin{tabular}{|c|c|c|c|}
\hline $\begin{array}{c}\text { Kuman } \\
\text { Türkçesi }\end{array}$ & $\begin{array}{c}\text { Memlûk } \\
\text { Türkçesi }\end{array}$ & Ermeni Kipçak Türkçesi & $\begin{array}{c}\text { Karay } \\
\text { Türkçesi }\end{array}$ \\
\hline- & - mIş -sA & - & - \\
\hline- & - & $-p$ e-se & - \\
\hline- & - & -GAn e-se & - \\
\hline
\end{tabular}

Bu birleşik zaman çekimi Kuman ve Karay Türkçelerinde görülmemektedir. Memlûk ve Ermeni Kıpçak Türkçelerinde tespit edilen duyulan geçmiş zaman kipinin şartında bu iki lehçe arasında farklılıklar bulunur. Memlûk Türkçesinde \{e-/er-\} ek-fiilinin bu birleşik zaman çekiminde düştüğü görülmektedir. Memlûk ve Ermeni Kıpçak Türkçelerinde kullanılan duyulan geçmiş zaman kip ekleri de yine bu iki lehçe arasinda farklılığı ortaya koyar.

\section{Geniş Zaman Kipinin Şartı}

\begin{tabular}{|c|c|c|c|}
\hline $\begin{array}{c}\text { Kuman } \\
\text { Türkçesi }\end{array}$ & $\begin{array}{c}\text { Memlûk } \\
\text { Türkçesi }\end{array}$ & Ermeni Kıpçak Türkçesi & $\begin{array}{c}\text { Karay } \\
\text { Türkçesi }\end{array}$ \\
\hline- & $-\mathrm{r}-\mathrm{sA}$ & $-\mathrm{r}$ e-se & - \\
\hline- & $-\mathrm{Ar}-\mathrm{sA}$ & $-\mathrm{Ar}$ e-se & - \\
\hline- & $-\mathrm{Xr}-\mathrm{sA}$ & $-\mathrm{Xr}$ e-se & - \\
\hline
\end{tabular}


Kuman ve Karay Türkçelerinde görülmeyen geniş zaman kipinin şartı, Memlûk ve Ermeni Kıpçak Türkçelerinde ortaklık göstermektedir.

\section{Gelecek Zaman Kipinin Şartı}

\begin{tabular}{|c|c|c|c|}
\hline $\begin{array}{c}\text { Kuman } \\
\text { Türkçesi }\end{array}$ & $\begin{array}{c}\text { Memlûk } \\
\text { Türkçesi }\end{array}$ & Ermeni Kıpçak Türkçesi & $\begin{array}{c}\text { Karay } \\
\text { Türkçesi }\end{array}$ \\
\hline- & -GAy e-se & - & - \\
\hline
\end{tabular}

Gelecek zaman kipinin şartı dört lehçe arasında sadece Memlûk Türkçesinde turgay èse 'kalkacaksa' (KTG 258) görülmektedir.

\section{Sonuç ve Değerlendirme}

Çalışmada yer alan veriler çerçevesinde ulaşlan sonuçlar maddeler halinde şu şekilde sıralanabilir:

Eski Türkçe döneminden itibaren tarihî ve çağdaş lehçelerde yaygın olarak kullanılan \{-mXş\} duyulan geçmiş zaman kip eki, Ermeni Kıpçak ve Karay Türkçelerinde bu işlevde görülmemektedir.

Karay Türkçesinde, duyulan geçmiş zaman kipi için sadece 3. şahıslarda \{-GAn\} eki kullanılır.

Kuman, Memlûk ve Ermeni Kıpçak Türkçelerinde geniş ve şimdiki zaman kipleri için müstakil ekler bulunurken; Karay Türkçesinde geniş ve şimdiki zaman kipleri aynı eklerle karşılanmaktadır.

Memlûk Kıpçak Türkçesinde şimdiki zaman kip ekleri arasında \{-yor/-yorur\} ekinin kullanılması Oğuz Türkçesinin bu lehçedeki etkisini gösteren bir durumdur.

Kuman, Memlûk ve Ermeni Kıpçak Türkçelerinde geniş zaman kipinin çekiminde kullanılan $\{-\mathrm{I}\},\{-\mathrm{U}\}$, $\{-\mathrm{Ar}\},\{-\mathrm{Xr}\}$ ve $\{-\mathrm{r}\}$ ekleri, Karay Türkçesinde gelecek zaman kipini karşllamaktadır.

Çağdaş Kıpçak lehçelerinde emir kipinin 2. teklik şahıs çekiminde yaygın kullanılan \{-GIn\} eki, Ermeni Kıpçak ve Karay Türkçelerinde düzenli kullanılan bir ektir.

Kuman, Memlûk ve Ermeni Kıpçak Türkçelerinde gelecek zaman kipinin çekiminde kullanılan \{-GAy\} eki, Karay Türkçesinde ince sıradan ünlüye geçerek istek kipi işlevinde kullanılır.

Gereklilik kipi dört lehçede de ortak olarak kerek elementi ile kurulur. kerek sözcügü ile kurulan bu yapının yanı sıra Ermeni Kıpçak Türkçesinde tiyäsidir/tiyişlidir ve tiyär modal sözleriyle gereklilik kip ekleri de oluşturulmuştur.

Karay Türkçesinde gereklilik kipi sadece 3. şahıs çekimlerde görülmektedir.

Ermeni Kıpçak Türkçesinde istek kipi için müstakil bir ek bulunmaz; emir kipi ile karşllanır.

Karay Türkçesinde gelecek zaman kipinin hikâyesi birleşik çekimi istek kipi ekleri ile yapılmaktadır.

Kuman Türkçesinde şimdiki zaman kipinin hikâyesi birleşik çekimi bulunmamaktadır.

Karay Türkçesinde görülen geçmiş zaman kipinin hikâyesi görülmez.

İstek kipinin hikâyesi birleşik çekimi dört lehçe de yoktur.

Gereklilik kipinin hikâyesi sadece Karay Türkçesinde görülmektedir.

Geniş zaman kipinin rivayeti ve gelecek zaman kipinin şartı sadece Memlûk Türkçesinde kullanılmaktadır.

Rivayet bildiren birleşik zamanlar Kuman, Ermeni Kıpçak ve Karay Türkçelerinde bulunmamaktadır.

Kuman ve Karay Türkçelerinde duyulan geçmiş zaman kipinin şartı ile geniş zaman kipinin şartına rastlanılmamaktadır. 
Çalışmada görülmektedir ki; kip eklerinin kullanımında bu dört lehçede standart bir ortaklıktan söz etmek mümkün değildir. Memlûk Türkçesinde şimdiki zaman kipinin kullanımında Oğuzca etkisi dikkate değer bir farklılık olarak göze çarpar. Karay Türkçesi ile diğer üç lehçe arasında en belirgin ayırt edicilik bazı kip eklerindeki işlevsel farklılıklardır. Dört lehçe arasında kip eklerinde görülen farklılıklar 18 maddede özetlenmiştir. Bu farklılıkların ortaya çıkmasında lehçelerin tarihî dönemleri, yayılma alanları, farklı din ve yabancı dil etkileşimleri önemli ölçüde etki ederken kimi zaman iç içe geçen Harezm-Kıpçak-Oğuz etkileşimi de bu sonucu ortaya çıaran nedenler arasında gösterilebilir.

\section{Kaynakça}

CC Argunşah, M., Güner, G. (2016), Codex Cumanicus, Kesit Yayınları, Ankara.

EHKT Kasapoğlu Çengel, H. (2012), "Ermeni Harfli Kıpçak Türkçesi”, Dil Araştırmaları, S. 10, s. 17-81.

KA Karay Awazı (1936), (ed.) Aleksander Mardkowicz, Luck, S. 9, s. 1-24.

KTD Gülsevin, S. (2016), Karay Türklerinin Dili, TDK Yayınları, Ankara.

KTG Güner, G. (2013), Kipçak Türkçesi Grameri, Kesit Yayınları, Ankara. 